\title{
Minimally invasive mediastinal staging of non- small cell lung cancer
}

\section{Kyungjong Lee, Sang-Won Um}

Division of Pulmonary and Critical Care Medicine, Department of Medicine, Samsung Medical Center, Sungkyunkwan University School of Medicine, Seoul, Korea

Received: January 11, 2018

Revised: February 14, 2018

Accepted: February 20, 2018

Corresponding author:

Sang-Won Um

Division of Pulmonary and

Critical Care Medicine,

Department of Medicine,

Samsung Medical Center,

Sungkyunkwan University

School of Medicine, 81 Irwon-

ro, Gangnam-gu, Seoul 06351,

Korea

Tel: +82-2-3410-3429

E-mail: sangwonum@skku.edu

\section{ABSTRACT}

Endobronchial ultrasound-guided transbronchial needle aspiration (EBUS-TBNA) is a minimally invasive procedure widely used for the diagnosis and staging of primary lung cancer. This review focuses on the role of EBUS-TBNA in minimally invasive mediastinal staging, restaging after induction therapy, and procedure-related issues. To better understand the role of EBUS-TBNA, one must consider issues of sedation and rapid onsite examination, sonographic features during the procedure, the number of aspirations per lymph node, and the thoroughness of the procedure. A literature review indicated that EBUS-TBNA showed equivalent or even superior performance to mediastinoscopy in the mediastinal staging of non-small cell lung cancer (NSCLC). Combining endoscopic ultrasound-guided fine needle aspiration (EUS-FNA) or the transesophageal approach using an EBUS bronchoscope (EUS-B-FNA) with EBUS-TBNA can provide additional diagnostic benefits. A recent guideline recommended endosonography over mediastinoscopy as the initial procedure for mediastinal nodal staging in patients with NSCLC with abnormal mediastinal and/or hilar lymph nodes on chest computed tomography (CT) or positron emission tomography/CT. The diagnostic sensitivity of EBUS-TBNA for restaging after induction therapy in patients with stage IIIA-N2 NSCLC was lower than that of initial staging. It appears reasonable to perform EBUS-TBNA first for initial mediastinal staging and reserve mediastinoscopy for restaging after induction therapy.

Keywords: Carcinoma, non-small-cell lung; Endobronchial ultrasound; Mediastinum; Staging
This is an Open Access article distributed under the terms of the Creative Commons Attribution Non-Commercial License (http:// creativecommons.org/licenses/ by-nc/4.0/).

\section{INTRODUCTION}

Lung cancer is the leading cause of cancer-related death in both male and female patients [1]. Mediastinal nodal staging plays a very important role in the management of non-small cell lung cancer (NSCLC) because it can predict patient survival and allow for the planning of an appropriate treatment strategy. The International Association for the Study of Lung Cancer (IASLC) has updated the TNM (tumor, node, and metastasis) staging system, including the mediastinal nodal map guidelines [2,3]. Mediastinal nodal staging of primary lung cancer is characterized from N0 to N3 according to the metastatic nodal stations from the primary tumor 
site. Mediastinal nodal staging before surgery includes noninvasive modalities, such as chest computed tomography (CT) and positron emission tomography (PET)/CT, or invasive surgical methods represented by mediastinoscopy. Endobronchial ultrasound-guided transbronchial needle aspiration (EBUS-TBNA) is a minimally invasive staging method and has had a major clinical impact on lung cancer staging since it was first reported in 2003 [4]. EBUS-TBNA has been used clinically for mediastinal nodal staging of NSCLC and restaging following induction treatment and for the diagnosis of benign or malignant mediastinal disease. This review focuses on the role of EBUS-TBNA in minimally invasive mediastinal staging, restaging after induction therapy, and procedure-related issues.

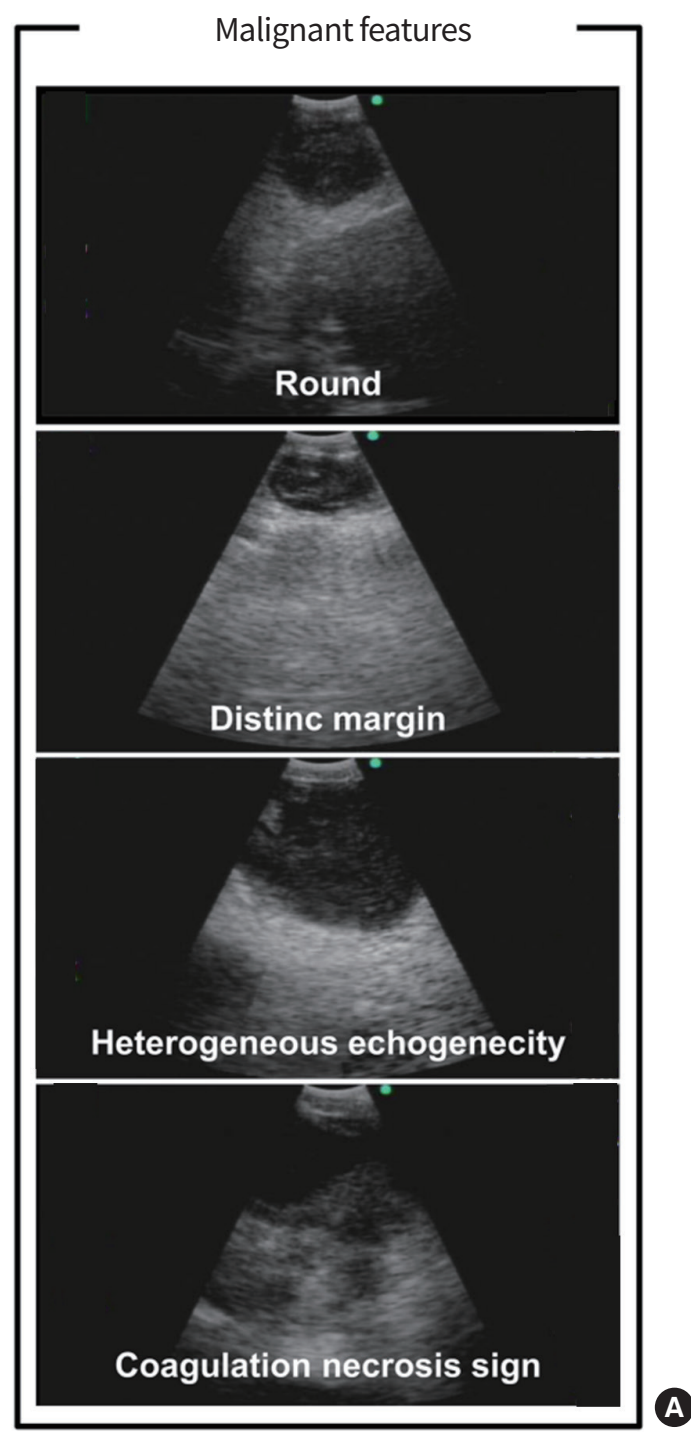

\section{PRACTICAL ISSUES FOR ACHIEVING HIGH ACCURACY BY EBUS-TBNA}

\section{Sedation for EBUS-TBNA}

EBUS-TBNA requires operator experience because the EBUS bronchoscope (EUS-B-FNA) must be inserted through the vocal cord with a $35^{\circ}$ forward oblique view. Furthermore, EBUS-TBNA requires more time to perform than flexible bronchoscopy. Thus, sedation is important for yielding the best diagnostic results with optimal patient comfort and minimizing related complications. In a randomized prospective trial of 149 patients, Casal et al. [5] reported no difference in diagnostic yield between a deep sedation group and a moderate sedation group. Another study by Dal et al. [6] also

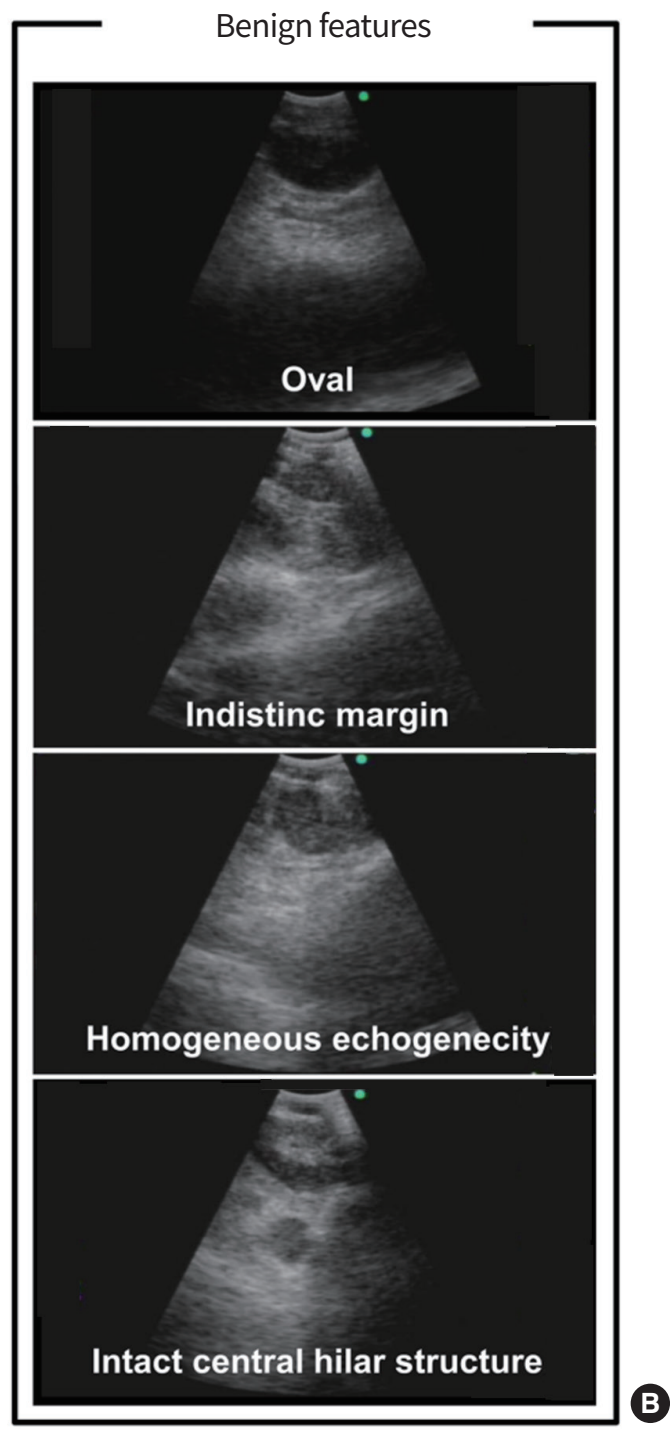

Fig. 1. (A) Malignant features include round shape, distinct margin, heterogeneous echogenecity, and coagulation necrosis sign. (B) Benign features include oval shape, indistinct margin, homogeneous echogenecity, and intact hilar structure. 
assessed patient comfort and satisfaction by sedation type (divided by ketamine-midazolam and ketamine-propofol combinations) and found no advantages in the deep sedation group. Therefore, moderate sedation appears to be sufficient for EBUS-TBNA.

\section{Training and learning curve}

After the EUS-B-FNA is inserted through the vocal cords, endosonography is performed to search for the target lymph nodes and a needle set is inserted into the working channel to obtain aspirates and core tissues from the target lesions. The different view and unique technique make it difficult for inexperienced users to obtain good-quality samples. Stather et al. [7] reported evidence of the effectiveness of an EBUS simulator compared to conventional training methods. A multicenter cohort study showed that fellows in pulmonary medicine could obtain adequate tissue after performing an average of 13 procedures [8]. However, there is significant variation in the learning curve in training fellows because about $33 \%$ did not achieve an expert level of technique during this training pro- gram [9]. In a randomized controlled trial, Konge et al. [10] suggested that virtual reality simulator training was more effective than traditional apprenticeship training.

\section{Sonographic features and elastography}

Another important issue is understanding the ultrasound features detected by EBUS. It is essential to discriminate the characteristics of benign and malignant lymph nodes on ultrasound images. Fig. 1 shows sonographic features for predicting metastatic lymph nodes, including a rounded shape, distinct margins, heterogeneous echogenicity, the presence of a coagulation necrosis sign, and a central hilar structure, as suggested by Fujiwara et al. [11]. However, in regions where tuberculous or anthracotic lymph nodes are prevalent, these criteria cannot clearly discriminate between benign and malignant lesions because benign lesions also show a heterogeneous echotexture and coagulation necrosis sign similar to those of metastatic lymph nodes (Fig. 2) $[12,13]$. Despite their imperfect ability to predict metastasis, sonographic features can help the bronchoscopist to select
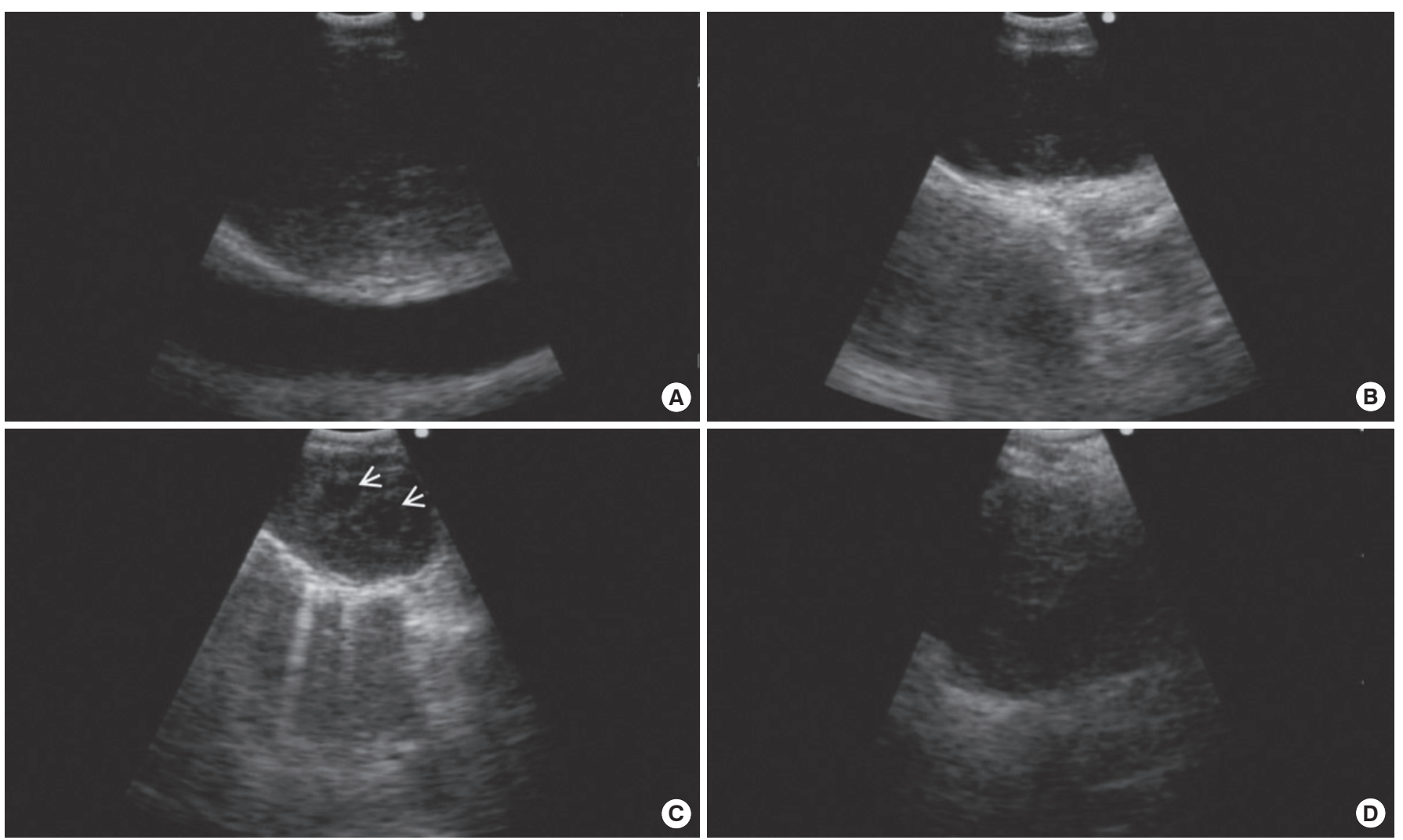

Fig. 2. Similarity of endobronchial ultrasound features of tuberculous lymphadenopathy and anthracotic lymph nodes compared to malignant lymph nodes. (A) A sonographic image of a metastatic node showed heterogeneous echogenicity. (B) Endobronchial ultrasound revealed a coagulation necrosis sign in the metastatic lymph node. (C) A coagulation necrosis sign (arrows) was observed in tuberculous lymphadenopathy. Mycobacterium tuberculosis was cultured in the lymph node aspirate. (D) An ultrasound image demonstrated heterogeneous echogenicity in the anthracotic lymph node. 
suspicious targets of most metastatic lymph nodes, particularly when the patient's condition does not allow for a full evaluation of lymph nodes. In previous studies, power/color Doppler-mode vascular image patterns were also helpful in predicting malignancy $[14,15]$. The presence of a central intranodal blood vessel suggests that the node is benign, whereas the absence of a central intranodal vessel increases the likelihood of malignancy [14]. The presence or absence of a central intranodal blood vessel has good overall accuracy in predicting malignancy (87.4\%) [14]. The blood flow from the bronchial artery toward the lymph node visualized as blue signals on EBUS color Doppler-mode images was also helpful in predicting malignancy, and the accuracy of predicting metastasis solely from a positive bronchial artery inflow sign was $80.3 \%$ [15].

Elastography has also been used to predict and localize metastatic lymph nodes during EBUS. Neoplastic tissue is usually stiffer than normal tissue, and elastography can generate images of stiffer tissue in metastatic lymph nodes. In a previous study, mean stiff area ratios were significantly greater for metastatic lymph nodes (0.478) than for benign lymph nodes (0.216; $P=0.0002)$, and the stiff area was histologically compatible with the metastatic distribution in surgically resected lymph nodes [16].

\section{Aspiration of lymph nodes}

The optimal number of aspirations to improve diagnostic yield is of considerable importance in mediastinal evaluation using EBUS-TBNA. In a prospective study that compared EBUS-TBNA and mediastinoscopy for mediastinal staging, EBUS-TBNA sampled an average of three (one to six) nodal stations in a clinical setting [17]. Although two reports regarding conventional TBNA indicated that a maximum of seven aspirations was sufficient for optimal diagnostic yield $[18,19]$, Lee et al. [20] suggested that optimal results could be obtained with three aspirations per lymph node station in EBUS-TBNA for mediastinal staging of potentially operable NSCLC when rapid onsite evaluation (ROSE) was not available. In this prospective study, three aspirations per node could reach a plateau of $100 \%$ adequacy and $95 \%$ sensitivity without additional yield after the fourth aspiration. When at least one tissue core specimen was obtained by the first or second aspiration, two aspirations per lymph node station were acceptable.

\section{Thoroughness of the procedure and ROSE}

The accuracy of mediastinal staging depends not only on which test is used but also on how the procedure is performed. Needle-based techniques, such as EBUS-TBNA and endoscopic ultrasound-guided fine needle aspiration (EUSFNA), can be divided into four categories according to sampled nodal stations, number of aspirations per node, and performance of ROSE: complete, systemic, selective, and poor sampling [21]. Complete sampling involves the sampling of each visible node at each station $(1,2 \mathrm{R}, 2 \mathrm{~L}, 3,4 \mathrm{R}, 4 \mathrm{~L}$, 7, 8, and 5, 6 if left upper lobe tumor), $\geq 3$ passes per node, or ROSE. Systemic sampling involves sampling nodes in each station (2R, 2L, 4R, 4L, 7, and 5, 6 if left upper lobe tumor) and $\geq 3$ passes per node or ROSE. Selective sampling involves biopsying one or more stations that must include a node suspicious on imaging analysis or $\geq 1 \mathrm{~cm}$ on ultrasonography if present, or $<3$ passes per node and no ROSE. Although complete sampling is ideal for mediastinal nodal staging, it has limitations in clinical practice during needle-based procedures because it prolongs the procedure time and may increase patient discomfort and procedure-related complications. However, to achieve optimal results, systemic nodal sampling should be performed using needle-based techniques [21].

\section{MINIMALLY INVASIVE MEDIASTINAL STAGING: EBUS-TBNA, EUS-FNA, AND EUS-B-FNA}

Mediastinal nodal staging before the treatment of lung cancer is clinically important, as it can guide the treatment strategy. Mediastinal nodal evaluation first involved noninvasive methods based on image analysis (such as chest CT and PET/ $\mathrm{CT}$ ), and then invasive methods (such as EBUS-TBNA, EUSFNA, or mediastinoscopy) were used to examine otherwise inaccessible tissues. Although chest $\mathrm{CT}$ and $\mathrm{PET} / \mathrm{CT}$ are now widely used in evaluating lung cancer and provide nodal information for the mediastinum, treatment decisions should not be made based on imaging studies alone because sensitivity and specificity for mediastinal staging are approximately $55 \%$ and $81 \%$, respectively, for chest CT and $62 \%$ and $90 \%$, respectively, for PET/CT [22]. Therefore, imaging findings suggestive of metastasis should be confirmed pathologically before treatment decisions are made. Minimally invasive needle techniques, such as EBUS-TBNA and EUS-FNA, have increasingly been used to stage the mediastinum. In contrast to mediastinoscopy, which requires general anesthesia, EBUS-TBNA can be performed safely under conscious sedation using midazolam and fentanyl. 


\section{EBUS-TBNA alone}

A convex EBUS-TBNA probe was first introduced in 2003 and showed sensitivity, specificity, and accuracy of $95.7 \%, 100 \%$, and $97.1 \%$, respectively [23]. It could distinguish benign from malignant lymph nodes with high diagnostic yields. A 2009 meta-analysis for staging of lung cancer that included a total 1,299 patients in 11 studies assessed the overall diagnostic accuracy of EBUS-TBNA and showed a pooled diagnostic sensitivity of $93 \%$ and pooled specificity of $100 \%$ [24]. These results suggest that mediastinal staging by EBUS-TBNA has better accuracy than chest $\mathrm{CT}$ and PET/CT scans. However, EBUS-TBNA could not evaluate station s 5, 6, 8, and 9 because of inaccessibility. These stations can be sampled by the transesophageal approach using EUS-FNA. Therefore, a combination of EBUS-TBNA and EUS-FNA is useful for complete and systematic mediastinal staging.

\section{EUS-FNA alone}

EUS-FNA is another minimally invasive method for mediastinal staging of NSCLC and was used prior to the introduction of EBUS-TBNA. Micames et al. [25] performed a meta-analysis of 18 eligible studies and reported pooled diagnostic sensitivity and specificity of EUS-FNA for NSCLC staging of $83 \%$ and $97 \%$, respectively. The median prevalence of malignant lymph nodes in this analysis was $65 \%$. They reported that the major limitation of this technique was an inability to access the $2 R, 3,4 R$, and 6 nodal stations, and they suggested using a combination of EBUS-TBNA and EUS-FNA to overcome this.

\section{Combined EBUS-TBNA and EUS-FNA}

EBUS-TBNA and EUS-FNA complement each other for nodal staging because nodal stations $2 \mathrm{~L}, 4 \mathrm{~L}, 5,7,8$, and 9 can be reached by EUS-FNA and nodal stations $1 R, 1 \mathrm{~L}, 2 \mathrm{R}, 2 \mathrm{~L} 3 \mathrm{P}, 4 \mathrm{R}$, $4 \mathrm{~L}, 7,10$, and 11 can be accessed by EBUS-TBNA. Combining the two techniques could lead to complete mediastinal staging because nearly all mediastinal stations, with the exception of stations 5 and 6 , can be accessed by the two techniques. A procedure involving a combination of transbronchial and transesophageal approaches has increasingly been used, and there have been no reports of serious complications. In a meta-analysis of eight studies with 821 patients, Zhang et al. [26] reported that the combined technique was more sensitive than EBUS-TBNA or EUS-FNA alone, with pooled diagnostic sensitivity and specificity of $86 \%$ and $100 \%$, respectively.

\section{Combined EBUS-TBNA and EUS-B-FNA}

Although combining EBUS-TBNA and EUS-FNA results in more accurate mediastinal nodal staging, it has several limitations in clinical practice. It requires expert endoscopists and equipment as well as additional costs and time for the evaluation. It would be ideal if EBUS-TBNA and EUS-FNA could be performed by the same operator. Hwangbo et al. [27] first reported the feasibility of the transesophageal approach using an EUS-B-FNA for lung masses and lymph nodes that were inaccessible by EBUS-TBNA and obtained additional diagnostic benefit. Lee et al. [28] also reported the additional value of EUS-B-FNA for patients with nodal stations inaccessible by EBUS-TBNA, and $13 \%$ of the patients examined by the combined approach were upstaged. A random effect meta-analysis showed that adding EUS-B-FNA to EBUS-TBNA increased sensitivity by $21 \%$ compared to EBUS-TBNA alone [29]. Another meta-analysis of 13 studies found additional value in the combination of EBUS-TBNA and EUS-(B)-FNA, with mean sensitivity of $86 \%$ for the combined approach [30]. There were no significant differences in mean sensitivity or negative predictive value between studies that used EBUS first or EUS first or between studies that used an EBUS-scope or a regular endoscope to perform EUS.

\section{EBUS-TBNA/EUS-FNA vs. mediastinoscopy}

Mediastinoscopy was the gold standard for invasive mediastinal staging prior to the introduction of the needle techniques. Mediastinoscopy requires general anesthesia and has morbidity and mortality rates of $2 \%$ and $<0.1 \%$, respectively. It has limited accessibility and only allows for an examination of stations $2 \mathrm{R}, 2 \mathrm{~L}, 4 \mathrm{R}, 4 \mathrm{~L}$, and 7 . Four prospective studies were performed to compare the diagnostic performance of endosonography and mediastinoscopy (Table 1). Ernst et al. [31] performed a crossover trial comparing the diagnostic performance of EBUS-TBNA and cervical mediastinoscopy in patients with suspected NSCLC. EBUS-TBNA had a higher overall diagnostic yield (91\%) compared to mediastinoscopy (78\%) in per lymph node analysis. There was disagreement in the yield between the two procedures in the subcarinal lymph nodes (24\%). In a prospective controlled trial by Yasufuku et al. [32] compared EBUS-TBNA to mediastinoscopy for mediastinal nodal staging of potentially resectable NSCLC; all patients underwent EBUS-TBNA followed by mediastinoscopy under general anesthesia. EBUS-TBNA and mediastinoscopy achieved similar results for mediastinal staging of NSCLC. Um et al. [17] conducted a prospective trial among patients with histologically proven NSCLC and sus- 
Table 1. Comparison of diagnostic performance between endosonography and mediastinoscopy in mediastinal nodal staging of non-small cell lung cancer

\begin{tabular}{|c|c|c|c|c|c|c|c|c|c|}
\hline \multirow{2}{*}{ Study } & \multirow{2}{*}{ No. } & \multirow{2}{*}{$\begin{array}{l}\text { Study } \\
\text { period }\end{array}$} & \multirow{2}{*}{ Study type } & \multirow{2}{*}{$\begin{array}{l}\text { Sedation during } \\
\text { endosonography }\end{array}$} & \multirow{2}{*}{$\begin{array}{c}\text { Prevalence } \\
\text { of N2/N3 } \\
\text { metastasis } \\
(\%)\end{array}$} & \multicolumn{2}{|c|}{$\begin{array}{c}\text { EBUS-TBNA or combined } \\
\text { EBUS-TBNA/EUS-FNA }\end{array}$} & \multicolumn{2}{|c|}{ Mediastinoscopy } \\
\hline & & & & & & $\begin{array}{c}\text { Sensitivity } \\
(\%)\end{array}$ & $\begin{array}{l}\text { NPV } \\
(\%)\end{array}$ & $\begin{array}{c}\text { Sensitivity } \\
(\%)\end{array}$ & $\begin{array}{l}\text { NPV } \\
(\%)\end{array}$ \\
\hline $\begin{array}{l}\text { Ernst et al. } \\
(2008)[31]^{\mathrm{a}, \mathrm{b})}\end{array}$ & 66 & 2005-2006 & $\begin{array}{l}\text { Prospective, } \\
\text { crossover trial }\end{array}$ & $\begin{array}{c}\text { Conscious sedation or } \\
\text { general anesthesia }\end{array}$ & 89.4 & 87 & 78 & 68 & 59 \\
\hline $\begin{array}{l}\text { Annema et al. } \\
(2010)[33]^{c)}\end{array}$ & 241 & 2007-2009 & $\begin{array}{l}\text { Prospective, } \\
\text { randomized trial }\end{array}$ & Conscious sedation & 42.7 & 85 & 85 & 79 & 86 \\
\hline $\begin{array}{l}\text { Yasufuku et al. } \\
\text { (2011) [32] }\end{array}$ & 153 & $2006-2010$ & $\begin{array}{l}\text { Prospective, } \\
\text { crossover trial }\end{array}$ & General anesthesia & 34.6 & 81 & 91 & 79 & 90 \\
\hline $\begin{array}{l}\text { Um et al. } \\
(2015)[17]\end{array}$ & 138 & 2010-2012 & $\begin{array}{l}\text { Prospective, } \\
\text { crossover trial }\end{array}$ & Conscious sedation & 59.1 & 88 & 85 & 81 & 79 \\
\hline
\end{tabular}

EBUS-TBNA, endobronchial ultrasound-guided transbronchial needle aspiration; EUS-FNA, endoscopic ultrasound-guided fine needle aspiration; NPV, negative predictive value.

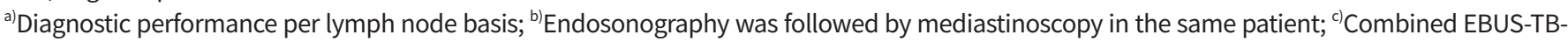
NA and EUS-FNA.

pected N1, N2, or N3 metastasis; each patient underwent EBUS-TBNA followed by mediastinoscopy. The diagnostic sensitivity of EBUS-TBNA was superior to that of mediastinoscopy (88.0\% vs. 81.3\%). EBUS-TBNA had higher diagnostic sensitivity, particularly in stations $4 \mathrm{~L}(81.0 \%$ vs. $52.4 \%)$ and 7 (82.5\% vs. $75.0 \%)$. Annema et al. [33] conducted a randomized controlled multicenter trial of 241 patients with resectable NSCLC to compare combined endosonography and mediastinoscopy. A combination of endosonography and surgical staging resulted in greater sensitivity for mediastinal nodal metastases ( $85 \%$ vs. $79 \%$, respectively) and fewer unnecessary thoracotomies ( $7 \%$ vs. $18 \%$, respectively) than surgical staging alone. Based on these prospective studies, recent guidelines published by ESGE/ERS/ESTS (European Society of Gastrointestinal Endoscopy/European Respiratory Society/ European Society of Thoracic Surgeons) recommend endosonography over mediastinoscopy as the initial procedure for mediastinal nodal staging in patients with NSCLC with abnormal mediastinal and/or hilar nodes on chest CT or PET/CT [29]. However, subsequent mediastinoscopy is recommended when endosonography does not show metastasis.

\section{Interpretation of negative results of endosonography} It is important to identify predictors of false-negative results on endosonography because patients with a high probability of false-negative results require confirmatory surgical staging. Talebian Yazdi et al. [34] evaluated 775 NSCLC patients with negative results by EBUS, EUS, or combined EBUS/EUS.
Central location of the lung tumor, enlarged node on $\mathrm{CT}$, and fluorodeoxyglucose avidity on PET were identified as predictors of false-negative results. In a retrospective study at a UK EBUS-TBNA center, lymph node standardized uptake value (SUV), SUV ratio between the primary tumor and lymph node, and heterogeneous echogenicity during sonographic assessment were independent predictors of false-negative results [35].

\section{EBUS-TBNA FOR RESTAGING AFTER IN- DUCTION TREATMENT IN IIIA-N2 NSCLC}

Although surgical resection after induction chemoradiotherapy in stage IIIA-N2 NSCLC showed no overall survival benefit in a phase III randomized trial [36], the role of surgery is still controversial because several reports have indicated a survival advantage in selected cases after surgical resection [37]. In a previous study of stage IIIA-N2 NSCLC, clearance of metastatic mediastinal lymph nodes (down-staging to NO/N1) after induction chemoradiotherapy was an independent prognostic factor in predicting the survival advantage of surgery [38]. Although restaging after induction treatment was conventionally performed using re-mediastinoscopy, it was not easy to detect residual metastatic lymph nodes because of mediastinal adhesion and fibrosis, with a disappointingly low sensitivity of $29 \%$ [39]. Instead of re-mediastinoscopy, endosonography was attempted to confirm the efficacy of restaging in IIIA-N2 NSCLC after induction therapy (Table 2). 


\section{PRECISION AND FUTURE MIEDICINE}

Mediastinal staging of NSCLC

Table 2. Outcomes of EBUS-TBNA for mediastinal restaging in patients with non-small cell lung cancer IIIA who underwent induction treatment

\begin{tabular}{|c|c|c|c|c|c|c|c|c|}
\hline \multirow{2}{*}{ Study } & \multirow{2}{*}{ No. } & \multirow{2}{*}{ Study period } & \multirow{2}{*}{ Study type } & \multirow{2}{*}{$\begin{array}{c}\text { Sedation } \\
\text { during EBUS-TBNA }\end{array}$} & \multirow{2}{*}{$\begin{array}{c}\text { Prevalence of } \\
\text { N2/N3 } \\
\text { metastasis (\%) }\end{array}$} & \multicolumn{3}{|c|}{$\begin{array}{c}\text { EBUS-TBNA or combined } \\
\text { EBUS-TBNA/EUS-FNA }\end{array}$} \\
\hline & & & & & & $\begin{array}{c}\text { Sensitivity } \\
(\%)\end{array}$ & $\begin{array}{l}\text { NPV } \\
(\%)\end{array}$ & $\begin{array}{c}\text { Accuracy } \\
(\%)\end{array}$ \\
\hline $\begin{array}{l}\text { Herth et al. } \\
(2008)[40]\end{array}$ & 124 & $2003-2006$ & Retrospective & $\begin{array}{c}\text { Conscious sedation, } \\
\text { general anesthesia }\end{array}$ & 94 & 76 & 20 & 77 \\
\hline $\begin{array}{l}\text { Nasir et al. } \\
\text { (2014) [41] }\end{array}$ & 27 & 2008-2012 & Retrospective & Conscious sedation & 33 & 50 & 88 & 89 \\
\hline $\begin{array}{l}\text { Szlubowski et al. } \\
(2014)[42]^{a)}\end{array}$ & 106 & 2009-2012 & Retrospective & Conscious sedation & 52 & 67 & 73 & 81 \\
\hline
\end{tabular}

EBUS-TBNA, endobronchial ultrasound-guided transbronchial needle aspiration; EUS-FNA, endoscopic ultrasound-guided fine needle aspiration; NPV, negative predictive value.

${ }^{a)}$ Combined EBUS-TBNA and EUS-FNA.

Herth et al. [40] reported that the diagnostic sensitivity of EBUS-TBNA for restaging was 76\% after induction chemotherapy. In a retrospective study of patients undergoing induction chemotherapy with or without radiotherapy, the sensitivity and negative predictive value of EBUS-TBNA for restaging were $50 \%$ and $88 \%$, respectively [41]. Combined EBUS-TBNA and EUS-B-FNA using a single ultrasound bronchoscope was attempted to restage patients with NSCLC after induction therapy and showed diagnostic sensitivity, negative predictive value, and accuracy of $67 \%, 73 \%$, and $81 \%$, respectively [42]. All patients in this study were confirmed by mediastinoscopy in cases of negative or uncertain results and metastatic lymph nodes were found in 18 of 69 patients with negative results by combined endosonography.

The diagnostic sensitivities of endosonography and re-mediastinoscopy for restaging were lower than those of initial staging in previous studies. Considering the better performance of mediastinoscopy when performed first, it appears reasonable to perform endosonography first for initial mediastinal staging and reserve mediastinoscopy for restaging. However, if endosonography is performed for restaging after induction therapy, negative results should be confirmed by mediastinoscopy considering the low negative predictive value of endosonography.

\section{CONCLUSION}

EBUS-TBNA is an essential modality for assessing the mediastinum of primary lung cancer with reduced invasiveness and improved safety. It should be performed with full under- standing of technical aspects, knowledge of indications, and interpretation of results. Combined EBUS-TBNA and EUSFNA or EUS-B-FNA could increase the diagnostic yield of EBUS-TBNA and replace the previous gold standard, mediastinoscopy, in the initial mediastinal nodal staging of NSCLC. However, patients with a high probability of false-negative results on EBUS-TBNA, such as those with a centrally located lung tumor, enlarged lymph node on chest $\mathrm{CT}$, or fluorodeoxyglucose avidity on $\mathrm{PET} / \mathrm{CT}$, require confirmatory mediastinoscopy. The diagnostic sensitivity of EBUS-TBNA for restaging after induction therapy in patients with stage IIIA-N2 NS$\mathrm{CLC}$ was lower than that of initial staging. It appears reasonable to perform EBUS-TBNA first for initial mediastinal staging and reserve mediastinoscopy for restaging after induction therapy.

\section{CONFLICTS OF INTEREST}

No potential conflict of interest relevant to this article was reported.

\section{REFERENCES}

1. Siegel RL, Miller KD, Jemal A. Cancer statistics, 2016. CA Cancer J Clin 2016;66:7-30.

2. Rusch VW, Asamura H, Watanabe H, Giroux DJ, Rami-Porta R, Goldstraw P, et al. The IASLC lung cancer staging project: a proposal for a new international lymph node map in the forthcoming seventh edition of the TNM classification for lung cancer. J Thorac Oncol 2009;4:568-77. 
3. Chansky K, Detterbeck FC, Nicholson AG, Rusch VW, Vallieres E, Groome P, et al. The IASLC lung cancer staging project: external validation of the revision of the tnm stage groupings in the eighth edition of the TNM classification of lung cancer. J Thorac Oncol 2017;12:1109-21.

4. Krasnik M, Vilmann P, Larsen SS, Jacobsen GK. Preliminary experience with a new method of endoscopic transbronchial real time ultrasound guided biopsy for diagnosis of mediastinal and hilar lesions. Thorax 2003;58:10836.

5. Casal RF, Lazarus DR, Kuhl K, Nogueras-Gonzalez G, Perusich S, Green LK, et al. Randomized trial of endobronchial ultrasound-guided transbronchial needle aspiration under general anesthesia versus moderate sedation. Am J Respir Crit Care Med 2015;191:796-803.

6. Dal T, Sazak H, Tunc M, Sahin S, Yilmaz A. A comparison of ketamine-midazolam and ketamine-propofol combinations used for sedation in the endobronchial ultrasound-guided transbronchial needle aspiration: a prospective, single-blind, randomized study. J Thorac Dis 2014;6:742-51.

7. Stather DR, Maceachern P, Rimmer K, Hergott CA, Tremblay A. Assessment and learning curve evaluation of endobronchial ultrasound skills following simulation and clinical training. Respirology 2011;16:698-704.

8. Wahidi MM, Hulett C, Pastis N, Shepherd RW, Shofer SL, Mahmood K, et al. Learning experience of linear endobronchial ultrasound among pulmonary trainees. Chest 2014;145:574-8.

9. Stather DR, Chee A, MacEachern P, Dumoulin E, Hergott CA, Gelberg J, et al. Endobronchial ultrasound learning curve in interventional pulmonary fellows. Respirology 2015;20:333-9.

10. Konge L, Clementsen PF, Ringsted C, Minddal V, Larsen KR, Annema JT. Simulator training for endobronchial ultrasound: a randomised controlled trial. Eur Respir J 2015;46:1140-9.

11. Fujiwara T, Yasufuku K, Nakajima T, Chiyo M, Yoshida S, Suzuki M, et al. The utility of sonographic features during endobronchial ultrasound-guided transbronchial needle aspiration for lymph node staging in patients with lung cancer: a standard endobronchial ultrasound image classification system. Chest 2010;138:641-7.

12. Jhun BW, Um SW, Suh GY, Chung MP, Kim H, Kwon OJ, et al. Clinical value of endobronchial ultrasound findings for predicting nodal metastasis in patients with suspected lymphadenopathy: a prospective study. J Korean Med
Sci 2014;29:1632-8.

13. Dhooria S, Agarwal R, Aggarwal AN, Bal A, Gupta N, Gupta D. Differentiating tuberculosis from sarcoidosis by sonographic characteristics of lymph nodes on endobronchial ultrasonography: a study of 165 patients. J Thorac Cardiovasc Surg 2014;148:662-7.

14. Satterwhite LG, Berkowitz DM, Parks CS, Bechara RI. Central intranodal vessels to predict cytology during endobronchial ultrasound transbronchial needle aspiration. J Bronchology Interv Pulmonol 2011;18:322-8.

15. Nakajima T, Anayama T, Shingyoji M, Kimura H, Yoshino I, Yasufuku K. Vascular image patterns of lymph nodes for the prediction of metastatic disease during EBUS-TBNA for mediastinal staging of lung cancer. J Thorac Oncol 2012;7:1009-14.

16. Nakajima T, Inage T, Sata Y, Morimoto J, Tagawa T, Suzuki $\mathrm{H}$, et al. Elastography for predicting and localizing nodal metastases during endobronchial ultrasound. Respiration 2015;90:499-506.

17. Um SW, Kim HK, Jung SH, Han J, Lee KJ, Park HY, et al. Endobronchial ultrasound versus mediastinoscopy for mediastinal nodal staging of non-small-cell lung cancer. J Thorac Oncol 2015;10:331-7.

18. Diacon AH, Schuurmans MM, Theron J, Brundyn K, Louw $\mathrm{M}$, Wright CA, et al. Transbronchial needle aspirates: how many passes per target site? Eur Respir J 2007;29:112-6.

19. Chin R Jr, McCain TW, Lucia MA, Cappellari JO, Adair NE, Lovato JF, et al. Transbronchial needle aspiration in diagnosing and staging lung cancer: how many aspirates are needed? Am J Respir Crit Care Med 2002;166:377-81.

20. Lee HS, Lee GK, Lee HS, Kim MS, Lee JM, Kim HY, et al. Real-time endobronchial ultrasound-guided transbronchial needle aspiration in mediastinal staging of non-small cell lung cancer: how many aspirations per target lymph node station? Chest 2008;134:368-74.

21. Detterbeck F, Puchalski J, Rubinowitz A, Cheng D. Classification of the thoroughness of mediastinal staging of lung cancer. Chest 2010;137:436-42.

22. Silvestri GA, Gonzalez AV, Jantz MA, Margolis ML, Gould MK, Tanoue LT, et al. Methods for staging non-small cell lung cancer: diagnosis and management of lung cancer, 3rd ed: American College of Chest Physicians evidencebased clinical practice guidelines. Chest 2013;143(5 Suppl):e211S-50S.

23. Yasufuku K, Chiyo M, Sekine Y, Chhajed PN, Shibuya K, lizasa $T$, et al. Real-time endobronchial ultrasound-guided transbronchial needle aspiration of mediastinal and 
hilar lymph nodes. Chest 2004;126:122-8.

24. Gu P, Zhao YZ, Jiang LY, Zhang W, Xin Y, Han BH. Endobronchial ultrasound-guided transbronchial needle aspiration for staging of lung cancer: a systematic review and meta-analysis. Eur J Cancer 2009;45:1389-96.

25. Micames CG, McCrory DC, Pavey DA, Jowell PS, Gress FG. Endoscopic ultrasound-guided fine-needle aspiration for non-small cell lung cancer staging: a systematic review and metaanalysis. Chest 2007;131:539-48.

26. Zhang R, Ying K, Shi L, Zhang L, Zhou L. Combined endobronchial and endoscopic ultrasound-guided fine needle aspiration for mediastinal lymph node staging of lung cancer: a meta-analysis. Eur J Cancer 2013;49:1860-7.

27. Hwangbo B, Lee HS, Lee GK, Lim KY, Lee SH, Kim HY, et al. Transoesophageal needle aspiration using a convex probe ultrasonic bronchoscope. Respirology 2009;14: 843-9.

28. Lee KJ, Suh GY, Chung MP, Kim H, Kwon OJ, Han J, et al. Combined endobronchial and transesophageal approach of an ultrasound bronchoscope for mediastinal staging of lung cancer. PLoS One 2014;9:e91893.

29. Vilmann P, Clementsen PF, Colella S, Siemsen M, De Leyn $P$, Dumonceau JM, et al. Combined endobronchial and esophageal endosonography for the diagnosis and staging of lung cancer: European Society of Gastrointestinal Endoscopy (ESGE) Guideline, in cooperation with the European Respiratory Society (ERS) and the European Society of Thoracic Surgeons (ESTS). Endoscopy 2015;47:54559.

30. Korevaar DA, Crombag LM, Cohen JF, Spijker R, Bossuyt PM, Annema JT. Added value of combined endobronchial and oesophageal endosonography for mediastinal nodal staging in lung cancer: a systematic review and meta-analysis. Lancet Respir Med 2016;4:960-8.

31. Ernst A, Anantham D, Eberhardt R, Krasnik M, Herth FJ. Diagnosis of mediastinal adenopathy-real-time endobronchial ultrasound guided needle aspiration versus mediastinoscopy. J Thorac Oncol 2008;3:577-82.

32. Yasufuku K, Pierre A, Darling G, de Perrot M, Waddell T, Johnston $\mathrm{M}$, et al. A prospective controlled trial of endobronchial ultrasound-guided transbronchial needle aspiration compared with mediastinoscopy for mediastinal lymph node staging of lung cancer. J Thorac Cardiovasc Surg 2011;142:1393-400.e1.

33. Annema JT, van Meerbeeck JP, Rintoul RC, Dooms C, Deschepper E, Dekkers OM, et al. Mediastinoscopy vs endosonography for mediastinal nodal staging of lung cancer: a randomized trial. JAMA 2010;304:2245-52.

34. Talebian Yazdi M, Egberts J, Schinkelshoek MS, Wolterbeek R, Nabers J, Venmans BJ, et al. Endosonography for lung cancer staging: predictors for false-negative outcomes. Lung Cancer 2015;90:451-6.

35. Evison M, Morris J, Martin J, Shah R, Barber PV, Booton R, et al. Nodal staging in lung cancer: a risk stratification model for lymph nodes classified as negative by EBUSTBNA. J Thorac Oncol 2015;10:126-33.

36. Albain KS, Swann RS, Rusch VW, Turrisi AT 3rd, Shepherd FA, Smith C, et al. Radiotherapy plus chemotherapy with or without surgical resection for stage III non-small-cell lung cancer: a phase III randomised controlled trial. Lancet 2009;374:379-86.

37. Pottgen C, Eberhardt W, Stamatis G, Stuschke M. Definitive radiochemotherapy versus surgery within multimodality treatment in stage III non-small cell lung cancer (NSCLC): a cumulative meta-analysis of the randomized evidence. Oncotarget 2017;8:41670-8.

38. Betticher DC, Hsu Schmitz SF, Totsch M, Hansen E, Joss C, von Briel C, et al. Mediastinal lymph node clearance after docetaxel-cisplatin neoadjuvant chemotherapy is prognostic of survival in patients with stage IIIA pN2 nonsmall-cell lung cancer: a multicenter phase II trial. J Clin Oncol 2003;21:1752-9.

39. De Leyn P, Stroobants S, De Wever W, Lerut T, Coosemans W, Decker $\mathrm{G}$, et al. Prospective comparative study of integrated positron emission tomography-computed tomography scan compared with remediastinoscopy in the assessment of residual mediastinal lymph node disease after induction chemotherapy for mediastinoscopy-proven stage IIIA-N2 non-small-cell lung cancer: a Leuven Lung Cancer Group Study. J Clin Oncol 2006;24:3333-9.

40. Herth FJ, Annema JT, Eberhardt R, Yasufuku K, Ernst A, Krasnik M, et al. Endobronchial ultrasound with transbronchial needle aspiration for restaging the mediastinum in lung cancer. J Clin Oncol 2008;26:3346-50.

41. Nasir BS, Bryant AS, Minnich DJ, Wei B, Dransfield MT, Cerfolio RJ. The efficacy of restaging endobronchial ultrasound in patients with non-small cell lung cancer after preoperative therapy. Ann Thorac Surg 2014;98:1008-12.

42. Szlubowski A, Zielinski M, Soja J, Filarecka A, Orzechowski S, Pankowski J, et al. Accurate and safe mediastinal restaging by combined endobronchial and endoscopic ultrasound-guided needle aspiration performed by single ultrasound bronchoscope. Eur J Cardiothorac Surg 2014; 46:262-6. 